\title{
Hepatocyte growth factor intervention to reduce myocardial injury and improve cardiac function on diabetic myocardial infarction rats
}

\author{
Zaiyong Zhang, ${ }^{1,2,3}$ Cheng Long, ${ }^{3}$ Yufeng Guan, ${ }^{4}$ Mingcai Song ${ }^{1,2}$ \\ ${ }^{1}$ Department of Cardiology, Panyu Central Hospital, Guangzhou \\ ${ }^{2}$ Cardiovascular Institute of Panyu District, Guangzhou \\ ${ }^{3}$ School of Life Sciences, South China Normal University, Guangzhou \\ ${ }^{4}$ Department of General Surgery, Panyu Central Hospital, Guangzhou, China
}

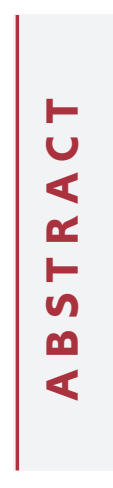

\begin{abstract}
Acute myocardial infarction (AMI) is recognized to be a severe threat to people's health conditions and life quality. The accumulation of hepatocyte growth factor (HGF) in ischemic myocardium has been observed in both processes of experimental ischemia and reperfusion $(\mathrm{I} / \mathrm{R})$ and permanent coronary artery occlusion. The aim of the study was to investigate the effect of HGF on myocardial cell apoptosis, ventricular remodeling and cardiac function after myocardial infarction (MI) in diabetic rats, and to explore whether the effect is mediated by HGF/c-Met signaling pathway. MI significantly increases LVWI and RVWI and myocardial apoptotic index, and up-regulates the expression of HGF and c-Met at mRNA and protein levels in MI control group. The LVWI and RVWI, and myocardial apoptosis were reduced by treatment with HGF, which also increased the myocardial cell viability and the expression of HGF and c-Met. In summary, HGF significantly attenuates myocardial apoptosis and improves cardiac function after AMI in diabetic rats by further enhancing the activation of HGF/c-Met pathway.
\end{abstract}

Key words: Diabetes mellitus; acute myocardial infarction; hepatocyte growth factor; c-Met.

Correspondence: Prof. Mingcai Song, Department of Cardiology, Panyu Central Hospital, Guangzhou, No.8 Fuyu East Avenue, Guangzhou 511400, China. Tel. +86.20.34859341 - Fax: +86.20 .34859340 .

E-mail: mingcaisong@yeah.net.

Contributions: ZZ, DH, YZ: experiments performing, data analysis, manuscript drafting; YZ, QX: samples collection assistance, experiments performing; ZZ, DH, CL, MS: study design and supervision, manuscript revision. All authors read and approved the final version and agreed to be accountable for all aspects of the work.

Conflict of interest: The authors declare that they have no conflict of interest.

Funding: This study was supported by the Natural Science Foundation of Guangdong Province General Project (NO. 2020A1515010277); the Guangzhou Medical and Health Science and Technology General Guidance Project (NO. 20201A011120 and NO. 20181A011116); the Panyu District Science and Technology Project (NO. 2018Z04-21, NO. 2018-Z04-51 and NO. 2019-Z04-89).

Ethics approval: All procedures involving animals were carried out in accordance with the Policy on the Care and Use of Animals by the Ethical Committee of Panyu Central Hospital Ethics Committee (SCXK 2013-0002).

Availability of data and materials: The data used to support the findings of this study are available from the corresponding author upon request. 


\section{Introduction}

Acute myocardial infarction (AMI) is recognized to be severe threats to people's health conditions and life quality. ${ }^{1}$ The threats are even much greater to diabetes mellitus (DM) patients, who, compared with non-DM patients, have shown significant worse prognosis and a higher death rate from AMI., ${ }^{2,3}$ The accumulation of hepatocyte growth factor (HGF) in ischemic myocardium has been observed in both processes of experimental ischemia and reperfusion $(\mathrm{I} / \mathrm{R})$ and permanent coronary artery occlusion. According to the study of Nakamuraand Mizuno, ${ }^{4}$ HGF plays an essential role in the post-myocardial infarction (MI) self-repair. Besides, recombining HGF or the gene transfer of HGF in the area of infarction has proved to be effective in ameliorating cardiac functions. ${ }^{5}$ Previous study have shown that HGF is not only expressed in the liver, but also in the heart and kidneys. ${ }^{6}$ HGF can be used by the recipient c-Met in the heart, playing an anti-inflammatory, anti-cardiomyocyte apoptosis and promoting vascular regeneration, improving ventricular reconstruction and heart function. ${ }^{6} \mathrm{HGF} / \mathrm{c}-$ Met pathway can also regulate the basal cellular redox status. ${ }^{7}$ In addition, $\mathrm{HGF} / \mathrm{c}-\mathrm{Met}$ signaling plays an important role in regulating the proliferation of muscle progenitors following injury. ${ }^{8,9}$ Nevertheless, there have been very few reports investigating how the heart functions and myocardial injury of diabetic rats can be affected by $\mathrm{HGF} / \mathrm{c}-\mathrm{Met}$ signaling pathway after MI. Therefore, this aim of the study was to explore the potential influence of HGF on the heart functions, ventricular remodeling and myocardial cell apoptosis of rats with both AMI and DM, and also examine the possible relationship between this effect and the $\mathrm{HGF} / \mathrm{c}-\mathrm{Met}$ signaling pathway.

\section{Materials and Methods}

\section{Rat diabetes model making and grouping}

The study was approved by Panyu Central Hospital Ethics Committee (2019-02). Eight-week-old Specific-pathogen free (SPF) grade SD rats were got from Guangdong medical laboratory animal center. The animal certificate number is: SCXK 2013-0002. They were housed 4 per cage in a room with a 12/12-hour light/dark cycle and an ambient temperature of 22 to $25^{\circ} \mathrm{C}$. After fasting for $12 \mathrm{~h}$, streptozotocin was injected into the abdominal cavity at a dose of $60 \mathrm{mg} / \mathrm{kg}$ as reported in previous studies. ${ }^{10,11} 72$ $\mathrm{h}$ after streptozotocin injection, blood was collected from the tail vein, and blood glucose was measured with a glucometer. The blood glucose was maintained at $16.8 \mathrm{mmol} / \mathrm{l}$ and stabilized for 5 d. The successful diabetic rats were randomly divided into sham operation group (S group), diabetic MI control group (MI group), and diabetic MI HGF intervention group (HGF+MI group).

\section{Ventricular mass index}

Four weeks after the operation, all the animals were anesthetized with $10 \%$ chloral hydrate, blood was collected from abdominal aorta, the heart was removed and washed, the right and left chambers were cut along the interventricular groove, the liquid was drained, and the mass of each part was measured by an electronic balance. The ventricular mass index was calculated as follows: i) Left ventricular heart mass index (LVWI) = left ventricular heart mass/body mass; ii) Right ventricular heart mass index $($ RVWI $)=$ right ventricular heart mass/body mass.

Some of the samples were routinely fixed with $4 \%$ buffered formalin for $2 \mathrm{~h}$ and embedded in paraffin, while from other fresh samples myocardial cells were isolated.

\section{Myocardial cell culture}

Myocardial tissues were dissociated and washed with F12/Dulbecco's modified Eagle's medium (DMEM) (Thermo Fisher Scientific, Waltham, MA, USA). The myocardial tissues were filtered through a 200-mesh screen after trypsin digestion. The supernatant was removed, and myocardial cell were resuspended into complete F12/DMEM medium, seeded in 24-well plates, and cultured at $37^{\circ} \mathrm{C}$ in a $5 \% \mathrm{CO}_{2}$ humidified atmosphere. The medium was replaced every three days, and cell morphology was daily observed.

\section{Hematoxylin and Eosin staining}

Myocardial sections from the formalin-fixed, paraffin-embedded blocks were de-waxed with xylene, and rehydrated with graded ethanol and distilled water, to be routinely stained with Hematoxylin and Eosin (HE). After staining, the sections were dried in oven at $37^{\circ} \mathrm{C}$, sealed with neutral gum, and observed under microscope for pathological changes.

\section{Fluorescent TUNEL assay}

De-waxed and rehydrated myocardial sections were treated with $20 \mu \mathrm{g} / \mathrm{mL}$ protease-free DNase $\mathrm{K}$ at $37^{\circ}$ for $15-30 \mathrm{~min}$. After 3-times washing with phosphate-buffered saline (PBS) or HBSS, the TUNEL assay solution was added (50 $\mu \mathrm{g}$ per sample) and incubated at $37^{\circ} \mathrm{C}$ in dark for $60 \mathrm{~min}$. The slides were mounted in a drop of anti-fading medium and observed in fluorescence microscopy (light excitation wavelength, 450-500 nm; green emission wavelength, 515-565 nm).

\section{Cell viability}

Conventional MTT assay was used to analyze cell viability. The myocardial cells separated from heart tissue were grown at 2$4 \times 10^{4}$ cells/well in 96-well microplates. The MTT solution (Sigma Chemical Co., St. Louis, MO, USA) was added to the medium (final concentration, $0.5 \mathrm{mg} / \mathrm{mL}$ ) and incubated at $37^{\circ} \mathrm{C}$ for $4 \mathrm{~h}$. The absorbance was measured at $450 \mathrm{~nm}$.

\section{Flow cytometry analysis}

The Annexin V-FITC/ propidium iodide (PI) Apoptosis Detection Kit (Becton Dickinson, Rutherford, NJ, USA) was used to quantify cellular apoptosis. Briefly, the cells were detached by mild trypsinization, resuspended in $200 \mu \mathrm{L}$ of annexin binding buffer containing $5 \mu \mathrm{L}$ PI and $10 \mu \mathrm{L}$ annexin V-FITC in the dark for $10 \mathrm{~min}$ at $25^{\circ} \mathrm{C}$. Flow cytometry (Abcam, Cambridge, MA, USA) was used to analyze the double-stained cells.

\section{Immunofluorescence}

The myocardial cells were cultured on sterile glass coverslips in 24 -well plates. The slides were fixed with $4 \%$ paraformaldehyde for $15 \mathrm{~min}$ at room temperature. The coverslips were washed with PBS and permeabilized for 20 min with $0.5 \%$ Triton X-100 in PBS. The cells were then incubated with primary antibodies including anti-HGF IgG and anti-c-Met IgG after blocking with 5\% BSA for $1 \mathrm{~h}$. The slides were incubated with Cy3-labeled Goat Anti-Mouse IgG and FITC-conjugated goat anti-rabbit IgG as the secondary antibody at room temperature for $1 \mathrm{~h}$. Slides were examined with a Nikon (Melville, NY, USA) Eclipse TE300 fluorescence microscope, and pictures were taken with a SPOT Diagnostic (Sterling Heights, MI, USA) CCD camera.

\section{SOD activity and $\mathrm{H}_{2} \mathrm{O}_{2}$ content in myocardial tissue and serum were deteted}

Mitochondria from cardiomyocytes were collected to measure SOD activity and $\mathrm{H}_{2} \mathrm{O}_{2}$ content using commercially available kits (Beyotime, Shanghai, China) and a microplate reader (SpectraMax M5) according to the manufacturer's instructions. 


\section{qPCR to detect mRNA expression of HGF and c-Met}

After total RNA extraction and reverse transcriptional reaction, we continued quantitative PCR reaction. $0.2 \mathrm{ml} \mathrm{PCR} \mathrm{tube}$ was taken and the reaction system was prepared as follows: PCR forward primer $(2 \mu \mathrm{M}) 2.0 \mu \mathrm{L}$, PCR reverse primer $(2 \mu \mathrm{M}) 2.0$ $\mu \mathrm{L}$, cDNA $2.0 \mu \mathrm{L}, 50 \times$ Rox Reference Dye $0.4 \mu \mathrm{L}$, ddH ${ }_{2} \mathrm{O} 3.6 \mu \mathrm{L}$. The PCR amplification were taken. At the end of the cycle, the melting curve was obtained from $55^{\circ} \mathrm{C}$ to $95^{\circ} \mathrm{C} 2^{\Delta \Delta \mathrm{CT}}$ method were used to analyze the result. Table 1 shows the sequences of the primers.

\section{Western blotting}

Myocardial cell proteins were examined via Western blotting by using the monoclonal antibody against the HGF and c-Met proteins (all 1:1000, Santa Cruz Biotechnology, Santa Cruz, CA, USA). GAPDH (1:5000, Sigma Chemical) served as a loading control. The secondary antibody of horseradish peroxidase (HRP)-labeled (1:1000, Santa Cruz) was used and incubated for one hour at $25^{\circ} \mathrm{C}$. The band density was quantified using the LICOR Odyssey infrared imaging system (LI-COR Bioscience, Lincoln, NE, USA).

\section{Statistical analysis}

All data are presented as the means \pm SD. Differences between multiple groups were analyzed using one-way ANOVA, followed by the Fisher's least significant difference (LSD) test. The significance level was set at $\mathrm{P}<0.05$.

\section{Results}

Comparation of cardiac mass index

According to the data, it can be seen that MI group presented significantly higher values of RVWI and LVWI compared with $\mathrm{S}$ and $\mathrm{HGF}+\mathrm{MI}$ groups $(\mathrm{P}<0.05)$. Besides, when comparing $\mathrm{S}$ and HGF+MI groups, the RVWI and LVWI values in the former group was lower than the latter $(\mathrm{P}<0.05)$ (Table 2). Based on these findings, it can be concluded that RVWI and LVWI increase with AMI, but this increase can be partially mitigated with HGF treatment.

\section{HE staining}

According to the observation after HE staining, the myocardial cells in S group had little inflammatory cell infiltration, uniform intercellular gaps, no broken filaments, good alignment and ordered arrangement. While in MI group, inflammatory cell infiltration was abundant, and myocardial cells presented disordered structure, broken filaments and decrease in cell number. In con-

Table 1. Sequences of the primers.

\begin{tabular}{llll} 
Gene ID & $\begin{array}{l}\text { Sequences } \\
\left(5^{\prime}-3^{\prime}\right)\end{array}$ & $\begin{array}{c}\text { Length } \\
(\mathrm{bp})\end{array}$ \\
$r$-HGF & NM_017017.2 & $\begin{array}{l}\text { Forward: ATGCAGTCAGCACCATCAA } \\
\text { Reverse: CCACCATAATCTCCTCACAAG }\end{array}$ & 102 \\
$r$-c-Met & NM_031517.2 & $\begin{array}{l}\text { Forward: CTGACGAGTGGAGACTCTGATA } \\
\text { Reverse: CTTGGACCAGCTCTGGATTTAG }\end{array}$ & 91 \\
\hline GAPDH & NM_017008.4 & $\begin{array}{l}\text { Forward: AGTTCAACGGCACAGTCAAG } \\
\text { Reverse: TACTCAGCACCAGCATCACC }\end{array}$ & 118 \\
\hline
\end{tabular}

Table 2. Cardiac mass index of each group (mean $\pm S D, n=6)$.

\begin{tabular}{lcc} 
Group & LWW ( $\mathrm{mg} / \mathrm{g})$ & RWWI $(\mathrm{mg} / \mathrm{g})$ \\
$\mathrm{S}$ & $2.34 \pm 0.02$ & $0.60 \pm 0.01$ \\
MI & $3.01 \pm 0.05^{*}$ & $0.90 \pm 0.01^{*}$ \\
\hline HGF+MI & $2.62 \pm 0.04^{* \#}$ & $0.71 \pm 0.01^{* \#}$ \\
\hline
\end{tabular}

${ }^{*} \mathrm{P}<0.05$ compared with sham group; ${ }^{\mathrm{P}}<0.05$ compared with MI group.

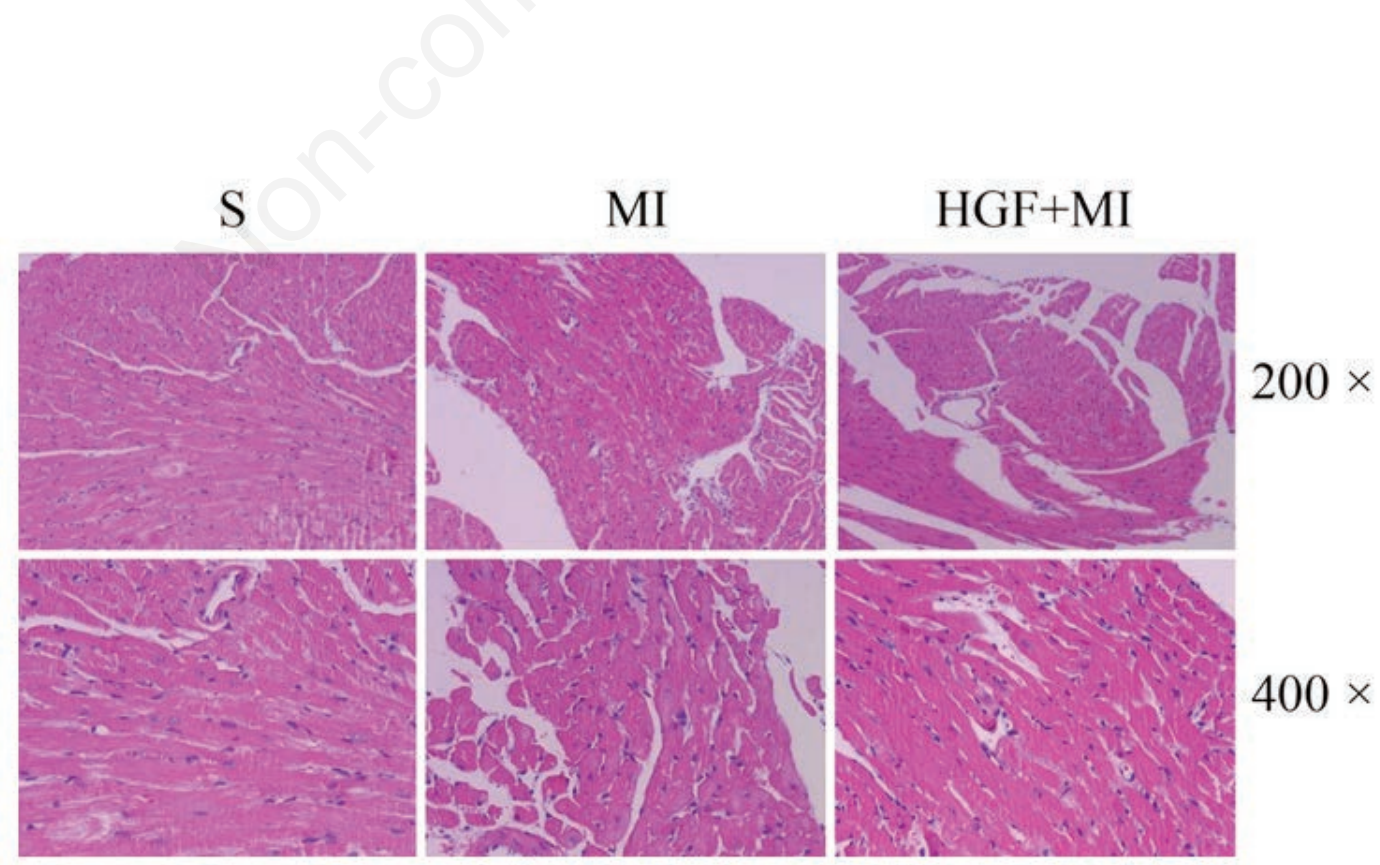

Figure 1. Images of tissues in each group after Hematoxylin \& Eosin (HE) staining, $200 \times$ and $400 \times . S$ group, sham operation group; MI group, diabetic myocardial infarction control group; HGF+MI group, diabetic myocardial infarction HGF intervention group. 
S
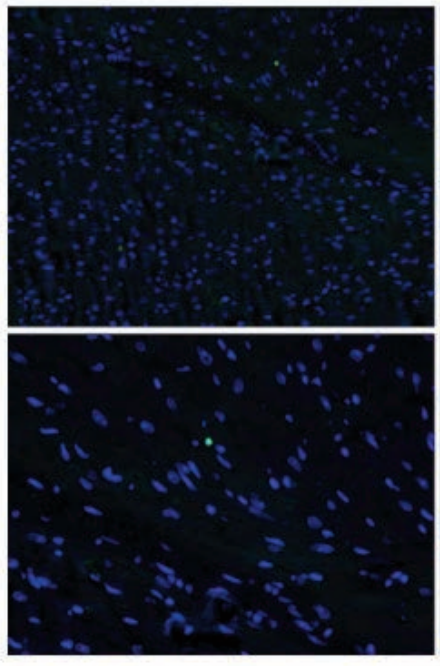

MI
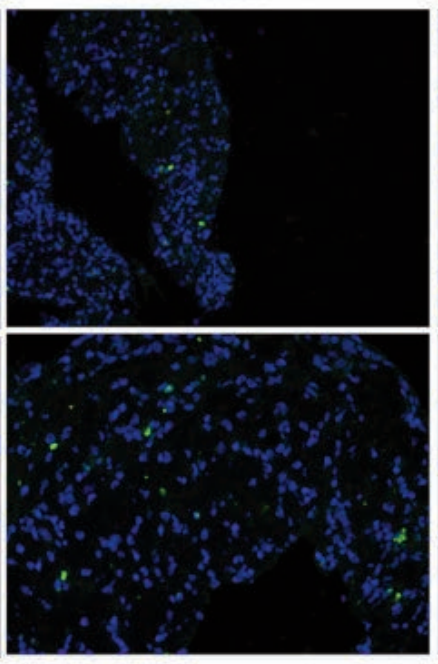

$\mathrm{HGF}+\mathrm{MI}$

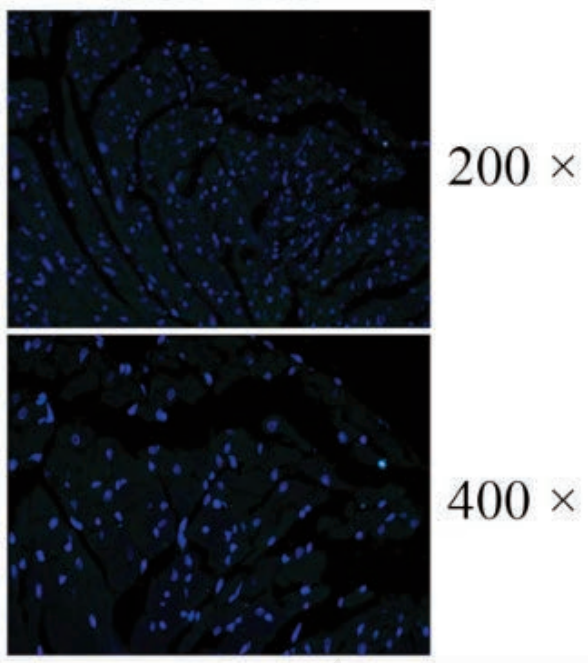

Figure 2. Images of tissues in each group after TUNEL staining, $200 \times$ and $400 \times . S$ group, sham operation group; MI group, diabetic myocardial infarction control group; HGF+MI group, diabetic myocardial infarction HGF intervention group.

trast, cells in the group with HGF treatment presented fewer characteristic changes, and the situations of inflammatory cell infiltration and disordered structures were alleviated (Figure 1).

\section{TUNEL staining}

The TUNEL assay was conducted for the detection of the apoptosis of myocardial cells. Based on the observation, the apoptosis in the $\mathrm{S}$ group was significantly severer than in the other two groups (Figure 2), which implies that HGF is effective in partially inhibiting MI-induced apoptosis of myocardial cells.

\section{SOD activity and $\mathrm{H}_{2} \mathrm{O}_{2}$ in myocardium and serum}

Based on the experiment data, MI group presented significant higher serum $\mathrm{H}_{2} \mathrm{O}_{2}$ values $(\mathrm{P}<0.05)$ and significantly lower serum and myocardium SOD values $(\mathrm{P}<0.05)$ compared with the other two groups, respectively (Table 3 ). Based on these findings, it can be concluded that MI deteriorates the injury in myocardium, while this pathological process can be mitigated with the treatment of HGF.

\section{Cell viability}

We further investage the cell viability of the myocardial cells by MTT assay. As shown in Figure 3, compared with the S group, the cell viability was markedly decreased in MI group $(\mathrm{P}<0.05)$, while the MI group treated with HGF, the cell viability was significantly increased $(\mathrm{P}<0.05)$. The results indicated that HGF protected the cardiomyocyte damage.

\section{Apoptosis rate}

In addition, we used the flow cytometry to evaluated the apoptosis rate of myocardial cells. From the results of the flow cytometry, the apoptosis rate in the MI group was markedly higher than that in S group, and after the MI group treatment with the HGF, the apoptosis rate was significantly decreased (Figure 4). The results imply that HGF is effective in partially inhibiting MI-induced apoptosis of myocardial cells.

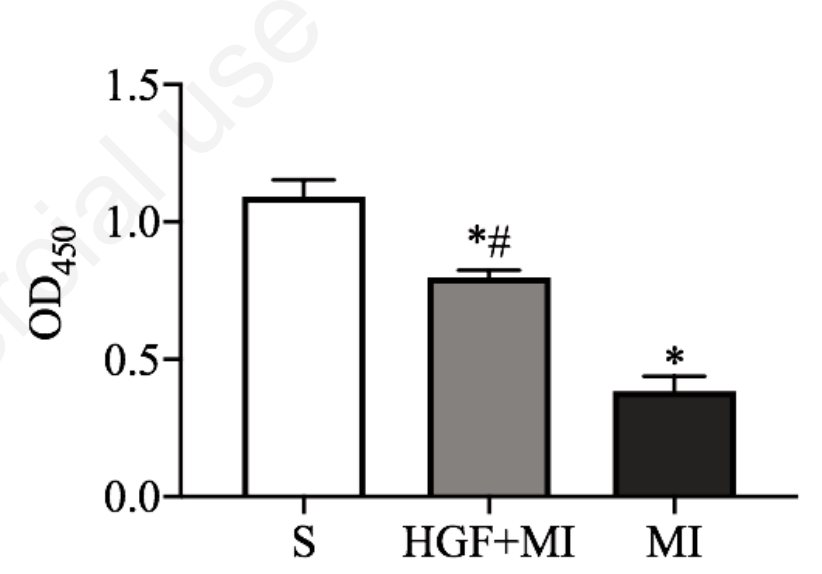

Figure 3. Cell viability evaluated by MTT assay in the three groups. S, sham operation group; MI, diabetic myocardial infarction control group; HGF+MI, diabetic myocardial infarction HGF intervention group. ${ }^{*} \mathbf{P}<\mathbf{0 . 0 5}$ compared with sham group; $\# \mathbf{P}<0.05$ compared with $\mathrm{MI}$ group.

Table 3. SOD activity and $\mathrm{H}_{2} \mathrm{O}_{2}$ in myocardium and serum of each group (mean $\pm S D, n=6)$.

\begin{tabular}{lccc} 
Group & $\begin{array}{c}\text { Serum SOD } \\
\text { (U/mL) }\end{array}$ & $\begin{array}{c}\text { Myocardium SOD } \\
\text { (U/mgprot) }\end{array}$ & $\begin{array}{c}\text { Serum } \mathrm{H}_{2} \mathrm{O}_{2} \\
(\mathrm{mM})\end{array}$ \\
S Group & $337.48 \pm 14.35$ & $1.93 \pm 0.29$ & $11.89 \pm 2.31$ \\
MI Group & $179.42 \pm 29.13^{*}$ & $0.98 \pm 0.10^{*}$ & $42.29 \pm 6.57^{*}$ \\
\hline HGF+MI Group & $256.31 \pm 22.00^{*, \#}$ & $1.47 \pm 0.08^{*, \#}$ & $22.84 \pm 5.86^{*, \#}$ \\
\hline
\end{tabular}

${ }^{*} \mathrm{P}<0.05$ compared with sham group; $\mathrm{P}<0.05$ compared with MI group. 


\section{HGF and c-Met mRNA expression in myocardial tissues}

Based on the data, the $\mathrm{S}$ group demonstrated significantly lower HGF and c-Met mRNA expression than the other two groups $(\mathrm{P}<0.05)$. Furthermore, the MI group showed significantly lower HGF and c-Met mRNA expression compared with the HGF group $(\mathrm{P}<0.05)$ (Figure 5). These findings imply that as the HGF and cMet mRNA expression has already been improved by MI, HGF treatment can further enhance this expression.

\section{HGF and c-Met protein expression in myocardial cells}

Western blot was used to detect the HGF and c-Met protein expression in the myocardial cells. Based on the data, the $\mathrm{S}$ group exhibited significantly lower HGF and c-Met protein expression than the other two groups $(\mathrm{P}<0.05)$. Moreover, the MI group showed markedly lower HGF and c-Met protein expression compared with the $\mathrm{HGF}+\mathrm{MI}$ group $(\mathrm{P}<0.05)$ (Figure 6). These findings imply that as the HGF and c-Met protein expressions are consistent with the HGF and c-Met mRNA expression in myocardial tissues.
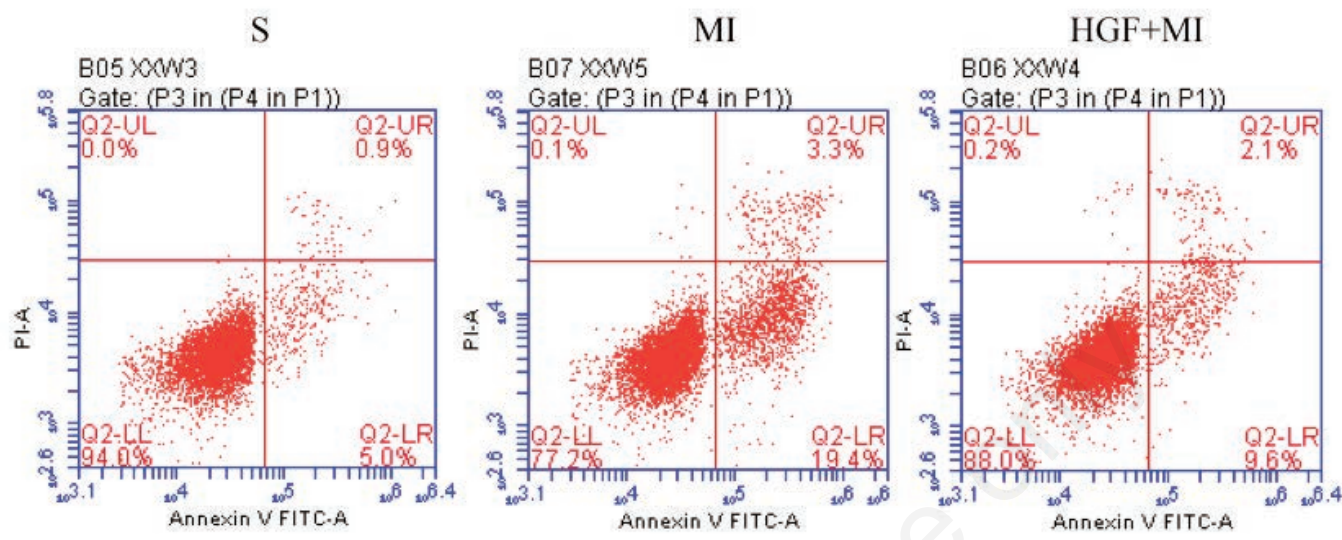

Figure 4. Apoptosis rate evaluated by the flow cytometry in the three groups. S, sham operation group; MI, diabetic myocardial infarction control group; HGF+MI, diabetic myocardial infarction HGF intervention group.
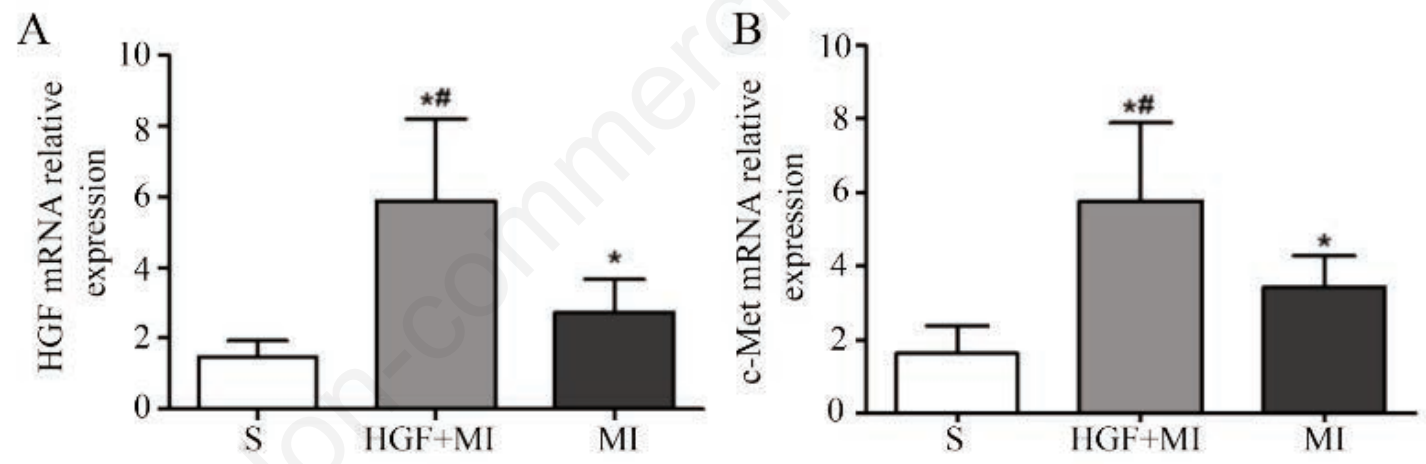

Figure 5. HGF and c-Met mRNA expression in myocardial tissues. $S$, sham operation group; MI, diabetic myocardial infarction control group; HGF+MI, diabetic myocardial infarction HGF intervention group. ${ }^{*} \mathrm{P}<0.05$ compared with sham group; \#P<0.05 compared with $\mathrm{MI}$ group.
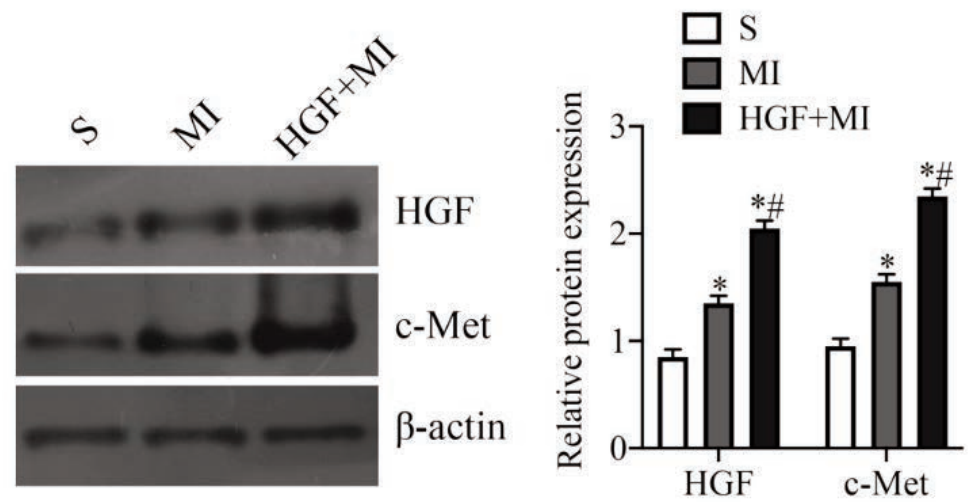

Figure 6. HGF and c-Met protein expression in myocardial tissues. S, sham operation group; MI, diabetic myocardial infarction control group; $\mathrm{HGF}+\mathrm{MI}$, diabetic myocardial infarction $\mathrm{HGF}$ intervention group. ${ }^{*} \mathrm{P}<0.05$ compared with sham group; \#P<0.05 compared with $\mathrm{MI}$ group. 


\section{Discussion}

For DM patients, AMI is recognized as a severe threat to their deteriorating heart functions. ${ }^{12,13} \mathrm{DM}$ has the effect of promoting the apoptosis of myocardial cells, fibrosis of myocardium, the AMI-induced expression of connective tissue growth factors and can also aggravate the post-AMI remodeling of myocardium. ${ }^{14,15}$ Previous researchers have demonstrated that HGF is effective in promoting angiogenesis and inhibiting apoptosis in organs like heart, lung and kidney, and can also accelerate the myocardial repair after MI. According to the studies of Guo et al. ${ }^{16} \mathrm{HGF}$ can promote angiogenesis and inhibit myocardial cell apoptosis, thus strengthening heart functions and enhancing ventricular remodeling. ${ }^{17}$ Komamura et al.,${ }^{18}$ has demonstrated the effectiveness of HGF in improving hypertension rates as well as the associated heart failure and arterial stiffness. Nevertheless, there have been very few scholars who have investigated how the heart functions and myocardial injury of diabetic rats can be affected by HGF after myocardial infarction. The findings in the present study show that HGF is effective in attenuating cardiac remodeling, apoptosis of myocardial cells and fibrosis of myocardium, as well as in enhancing heart functions of DM rates after MI.

Based on the treatment performance of currently adopted HGF gene therapy, transplanted HGF-transfected cells are effective in enhancing heart functions and promoting post-AMI cardiac remodeling. ${ }^{19}$ According to Yuan et al.,${ }^{20}$ micro-bubble-transported HGF treatment is effective in reducing the content of myocardial collagen and mass of left ventricle, as well as in increasing the density of capillary. This report has introduced China's current advancement in the clinical trials of adenovirus and plasmid HGF in treating coronary heart disease and critical limb ischemia. Besides, this report has also provided an insight in the prospective new regenerative strategies with the use of HGF-modified mesenchymal stem cells. ${ }^{21}$ HGF gene therapy has been recognized as an approach with strong potential to treat ischemic diseases and to be applied to regenerative medicine. ${ }^{22}$

Additionally, $\mathrm{HGF} / \mathrm{c}-\mathrm{MET}$ signaling has been reported to play a role in sarcoma formation. ${ }^{23,24}$ The deregulation of HGF/c-Met signaling axis has been observed in various types of cancer, which is of great importance in the metastasis and invasion of tumor cells. ${ }^{25}$ So far, HGF/c-Met signaling pathway is widely applied to heart protection. Ono ${ }^{26}$ firstly demonstrated that reperfusion and ischemia of myocardium are inductive to the expression of HGF in different organs in vivo. Onitsuka et al. also suggested the critical role of $\mathrm{HGF} / \mathrm{c}-\mathrm{Met}$ in the capillary endothelial cell regeneration in the heart with ischemic injury. ${ }^{27}$ According to Ueda et al.,${ }^{28}$ in heart with ischemic injury, the upregulation of c-Met/HGF receptor mRNAs can be detected, and it is highly possible that cardiac tissues are influenced by the cytoprotective effect of HGF, which is probably administered via a c-Met/HGF receptor. The present study has yielded consistent results that HGF treatment is effective in further increasing c-Met and HGF's mRNA levels, which have already been increased due to MI, in tissues of myocardium.

However, there are some shortcomings in our experiment: we have only conducted HGF has a significant effect in inhibiting the apoptosis and the expressions of c-Met/HGF, and evidence of experiments is needed to further determine that the mechanism of the effect of HGF on apoptosis via c-Met/HGF pathway.

Therefore, based all the findings and discussions above, it can be concluded that HGF has a significant effect in inhibiting the apoptosis of myocardium and enhancing heart functions of DM rats with AMI via further improving by further enhancing $\mathrm{HGF} / \mathrm{c}-\mathrm{Met}$ pathway activation.

\section{References}

1. Aniwan S, Pardi DS, Tremaine WJ, Loftus EV, Jr. Increased risk of acute myocardial infarction and heart failure in patients with inflammatory bowel diseases. Clin Gastroenterol Hepatol 2018;16:1607-15.

2. Echouffo-Tcheugui JB, Kolte D, Khera S, Aronow HD, Abbott JD, Bhatt DL, et al. Diabetes mellitus and cardiogenic shock complicating acute myocardial infarction. Am J Med 2018;131:778-86.

3. Sardella G, Mancone M, Stio RE, Cavallo E, Di Roma A, Colantonio R, et al. Prasugrel or ticagrelor in ST-segment-elevation myocardial infarction patients with diabetes mellitus. Circulation 2017;136:602-4.

4. Nakamura T, Mizuno S. The discovery of hepatocyte growth factor (HGF) and its significance for cell biology, life sciences and clinical medicine. Proc Jpn Acad Ser B Phys Biol Sci 2010;86:588-610.

5. Otsuki Y, Nakamura Y, Harada S, Yamamoto Y, Ogino K, Morikawa K, et al. Adipose stem cell sheets improved cardiac function in the rat myocardial infarction, but did not alter cardiac contractile responses to beta-adrenergic stimulation. Biomed Res 2015;36:11-9.

6. Sala V, Crepaldi T. Novel therapy for myocardial infarction: can HGF/Met be beneficial? Cell Mol Life Sci 2011;68:1703-17.

7. Clavijo-Cornejo D, Enriquez-Cortina C, López-Reyes A, Dominguez-Perez $M$, Nuno N, Dominguezmeraz $M$, et al. Biphasic regulation of the NADPH oxidase by HGF/c-Met signaling pathway in primary mouse hepatocytes. Biochimie 2013;95:1177-84.

8. Webster MT, Fan C. c-MET regulates myoblast motility and myocyte fusion during adult skeletal muscle regeneration. PLoS One 2013;8:11-20.

9. Van Mater D, Ano L, Blum JM, Webster MT, Huang W, Williams N, et al. Acute tissue injury activates satellite cells and promotes sarcoma formation via the $\mathrm{HGF} / \mathrm{c}-\mathrm{MET}$ signaling pathway. Cancer Res 2015;75:605-14.

10. Borriello SP, Heaton S, Drasar BS. Antibiotic susceptibility testing of anaerobes: comparison of three methods, including an automated micro-method, and evaluation of the effect of different media. J Appl Microbiol 1979;46:57-63.

11. Kolb H, Oschilewski M, Schwab E, Oschilewski U, Kiesel U. Effect of cyclosporin A on low-dose streptozotocin diabetes in mice. Diabetes Res 1985;2:191-200.

12. Skrlec I, Milic J, Cilensek I, Petrovic D, Wagner J, Peterlin B. Circadian clock genes and myocardial infarction in patients with type 2 diabetes mellitus. Gene 2019;701:98-103.

13. Beckman JA, Creager MA, Libby P. Diabetes and atherosclerosis: epidemiology, pathophysiology, and management. JAMA 2002;287:2570-81.

14. Jakobsson S, Bergstrom L, Bjorklund F, Jernberg T, Soderstrom L, Mooe T. Risk of ischemic stroke after an acute myocardial infarction in patients with diabetes mellitus. Circ Cardiovasc Qual Outcomes 2014;7:95-101.

15. Verdoia M, Barbieri L, Schaffer A, Cassetti E, Di Giovine G, Nardin M, et al. Effect of diabetes mellitus on periprocedural myocardial infarction in patients undergoing coronary stent implantation. Diabetes Metab Res Rev 2015;31:85-92.

16. Guo G, Narayan RN, Horton L, Patel TR, Habib AA. The role of EGFR-Met interactions in the pathogenesis of glioblastoma and resistance to treatment. Curr Cancer Drug Targets 2017; 17:297-302.

17. Tang J, Wang J, Guo L, Kong X, Yang J, Zheng F, et al. Mesenchymal stem cells modified with stromal cell-derived factor $1 \alpha$ improve cardiac remodeling via paracrine activation 
of hepatocyte growth factor in a rat model of myocardial infarction. Mol Cells 2010;29:9-19.

18. Komamura K, Tatsumi R, Miyazaki J, Matsumoto K, Yamato E, Nakamura T, et al. Treatment of dilated cardiomyopathy with electroporation of hepatocyte growth factor gene into skeletal muscle. Hypertension 2004;44:365-71.

19. Poppe A, Golsong P, Blumenthal B, Von Wattenwyl R, Blanke $\mathrm{P}$, Beyersdorf F, et al. Hepatocyte growth factor-transfected skeletal myoblasts to limit the development of postinfarction heart failure. Artif Organs 2012;36:238-46.

20. Yuan X, Wang X, Chen C, Zhou J, Han M. Bone mesenchymal stem cells ameliorate ischemia/reperfusion-induced damage in renal epithelial cells via microRNA-223. Stem Cell Res Ther 2017;8:146-59.

21. Wang L-S, Wang H, Zhang Q-L, Yang Z-J, Kong F-X, Wu CT. Hepatocyte growth factor gene therapy for ischemic diseases. Hum Gene Ther 2018;29:413-23.

22. Gaffney MM, Hynes SO, Barry F, O'brien T. Cardiovascular gene therapy: current status and therapeutic potential. Brit J Pharmacol 2007;152:175-88.

23. Rong S, Jeffers M, Resau JH, Tsarfaty I, Oskarsson M, Woude GFV. Met expression and sarcoma tumorigenicity. Cancer Res
1993;53:5355-60.

24. Taulli R, Scuoppo C, Bersani F, Accornero P, Forni PE, Miretti $\mathrm{S}$, et al. Validation of Met as a therapeutic target in alveolar and embryonal rhabdomyosarcoma. Cancer Res 2006;66:4742-9.

25. Ma PC, Tretiakova MS, Nallasura V, Jagadeeswaran R, Husain AN, Salgia R. Downstream signalling and specific inhibition of c-MET/HGF pathway in small cell lung cancer: implications for tumour invasion. Brit J Cancer 2007;97:368-77.

26. Ono K, Matsumori A, Shioi T, Furukawa Y, Sasayama S. Enhanced expression of hepatocyte growth factor/c-Met by myocardial ischemia and reperfusion in a rat model. Circulation 1997;95:2552-8.

27. Onitsuka T, Uramoto H, Ono K, Takenoyama M, Hanagiri T, Oyama $\mathrm{T}$, et al. Comprehensive molecular analyses of lung adenocarcinoma with regard to the epidermal growth factor receptor, K-ras, MET, and hepatocyte growth factor status. J Thorac Oncol 2010;5:591-6.

28. Ueda H, Nakamura T, Matsumoto K, Sawa Y, Matsuda H, Nakamura T. A potential cardioprotective role of hepatocyte growth factor in myocardial infarction in rats. Cardiovasc Res 2001;51:41-50.

Received for publication: 25 May 2020. Accepted for publication: 29 June 2020.

This work is licensed under a Creative Commons Attribution-NonCommercial 4.0 International License (CC BY-NC 4.0).

(C) Copyright: the Author(s), 2020

Licensee PAGEPress, Italy

European Journal of Histochemistry 2020; 64(s2):3142

doi:10.4081/ejh.2020.3142 